\title{
Challenges Associated with Classifying Urban Meteorological Stations: The Oklahoma City Micronet Example
}

\author{
Amanda J. Schroeder*, Jeffrey B. Basara and Bradley G, Illston
}

Oklahoma Climatological Survey, University of Oklahoma, Oklahoma Climatological Survey, 120 David L. Boren Blvd. Suite 2900, Norman, OK 73072, USA

\begin{abstract}
During 2007-2008, a dense network of meteorological stations was deployed across the Oklahoma City metropolitan area to collect real-time, research-quality observations of atmospheric variables throughout the urban environment: the Oklahoma City Micronet (OKCNET). Because surface characteristics can be vastly different between rural and urban areas as well as throughout a city, significant variability exists in the local microclimates observed by meteorological stations deployed in an urban area. As such, documenting the characteristics near any site (i.e., metadata) is critical to fully understand the overall representativeness of the site and the associated evolution of atmospheric conditions. To date, a universal classification system for urban meteorological stations does not exist. Thus, this study utilized four different methodologies to classify OKCNET sites and increase the metadata for the individual sites and the overall network. The results demonstrated that while each classification system had specific merits, significant challenges existed in establishing consistent metadata for the sites due to (a) limitations associated with the methodologies and (b) the heterogeneity of surface conditions. In particular, stations deployed within the transition zones form urban to suburban and suburban to rural posed the greatest challenges in establishing consistent metadata for the sites.
\end{abstract}

Keywords: Oklahoma City micronet, urban, site classification, metadata.

\section{INTRODUCTION}

Urban-industrial complexes have changed dramatically in a relatively short period [1] and many atmospheric conditions have been modified within the urban environment including airflow [2,3] albedo and emissivity [4-6], humidity $[7,8]$, precipitation $[9,10]$, and roughness length $[11$, 12]. Because of the varied surface conditions between urban and rural zones, urban areas worldwide have yielded warmer conditions when compared to nearby rural areas [13-15]. This phenomenon, known as the urban heat island, results from differential thermal storage between rural and urban areas [16] and is most prominent at night and under synoptic high-pressure systems [16-19].

While the effects of urbanization vary from city to city, contributing factors include population and building density [20-22], land use [23, 24], city size [20] industrial level, and traffic patterns [18]. Further, urban growth is heterogeneous both spatially and temporally [25], and with nearly twothirds of the United States population residing in urban areas occupying less than two percent of the landmass, a detailed understanding of atmospheric processes in urban areas is critically important [26]. Not only is the awareness of impending weather changes beneficial to daily planning and emergency management for millions of urban residents, but overall public health is also impacted by local urban weather and climate. For example, many deaths due to heat extremes in urban areas could be avoided by more specific and

*Address correspondence to this author at the Oklahoma Climatological Survey, University of Oklahoma, Oklahoma Climatological Survey, 120 David L. Boren Blvd. Suite 2900, Norman, OK 73072, USA; Tel: 405-3252541; Fax: 405-325-2550; E-mail: schroeder@ou.edu accurate forecasts, advisories, and warnings [27-29]. To achieve such increased levels of urban-atmospheric awareness and the growing need for general meteorological services that impact building and urban design [30], energy conservation, transport and communications, air quality and health $[27,28]$, storm water and engineering, insurance and emergency measures [26], increased real-time researchquality observations must be collected that represent the spectrum of urban climate regions within a city [31]. However, because the urban-atmosphere interface is very complex, representative measurements are often difficult to collect [32].

In 2008, a network of meteorological stations was commissioned to collect research-quality observations of atmospheric variables in Oklahoma City: the Oklahoma City Micronet (OKCNET). As part of the long-term operations of OKCNET, the collection of station metadata was identified as a critical need. Thus, beginning with the original deployment of sensors, supplemental information for each station was collected including site photographs and general geographical information. Using the collected information, each station was classified according to methodologies published by Auer [33], Ellefsen [30], Oke [31], and Stewart and Oke [34]. However, significant classification challenges arose pertaining to a number of sites deployed across Oklahoma City and this study documents the strengths, limitations, and possible needs for future classification schemes focused on urban meteorological stations.

\section{METHODOLOGY}

Deployed in 2008, OKCNET is a network of automated meteorological stations that measure atmospheric variables throughout the Oklahoma City metropolitan area. The 40- 
station network consists of four Oklahoma Mesonet Stations [35] and 36 stations mounted on traffic signals at a height of approximately $9 \mathrm{~m}$ and station spacing of approximately 3 $\mathrm{km}[36]$.

Each Oklahoma Mesonet station measures core parameters that include: air temperature and relative humidity at $1.5 \mathrm{~m}$, wind speed and direction at $10 \mathrm{~m}$, atmospheric pressure, downwelling solar radiation, rainfall, and bare and vegetated soil temperatures at $10 \mathrm{~cm}$ below ground level. In addition, each Mesonet site deployed as part of OKCNET includes sensors to measure air temperature at $9 \mathrm{~m}$. All Oklahoma Mesonet data are collected and transmitted to a central point every 5 minutes where they are quality controlled, distributed and archived [35, 37, 38].

At each OKCNET traffic signal site, atmospheric conditions of air temperature, humidity, pressure, rainfall, wind speed, and wind direction at $9 \mathrm{~m}$ are measured and transmitted every minute to a central facility where they are quality controlled, distributed, and archived using the Oklahoma Mesonet infrastructure. The Oklahoma City Micronet includes a cluster of stations within the central business district as well as stations throughout the Metropolitan area (Fig. 1).

Stewart and Oke [34] noted that important station metadata was excluded for most urban heat island studies.
Based on their review of over 180 studies published between 1950 and 2007, one third of the articles failed to provide either a qualitative or quantitative description of the sites used while the remaining two thirds only included qualitative site descriptions. Because (a) local climates can vary significantly within a metropolitan area and (b) the signal of an urban heat island greatly depends on the available sites $[14,39]$, including this valuable metadata is crucial for accurately quantifying the results of the research conducted. Oke [40] noted that if a simple, common classification system were in place, scientists with no direct experience with the sites used in a particular study could gain an appreciation of site characteristics and have an objective basis on which to include or exclude that data.

Because multiple methods exist yielding varying guidelines to classify urban meteorological sites, four differing systems were applied to OKCNET to create as thorough a metadata dataset as possible. For example, Auer [33] developed a qualitative urban classification system based upon "meteorologically oriented" land use and land cover parameters with the goal of keeping the system general enough to be applied to virtually any metropolitan area. Using low-level airborne mapping and photography, the land use and land cover parameters were established for the St. Louis urban area in the mid-seventies. Later, Ellefsen [30] created an Urban Terrain Zone system because the overall

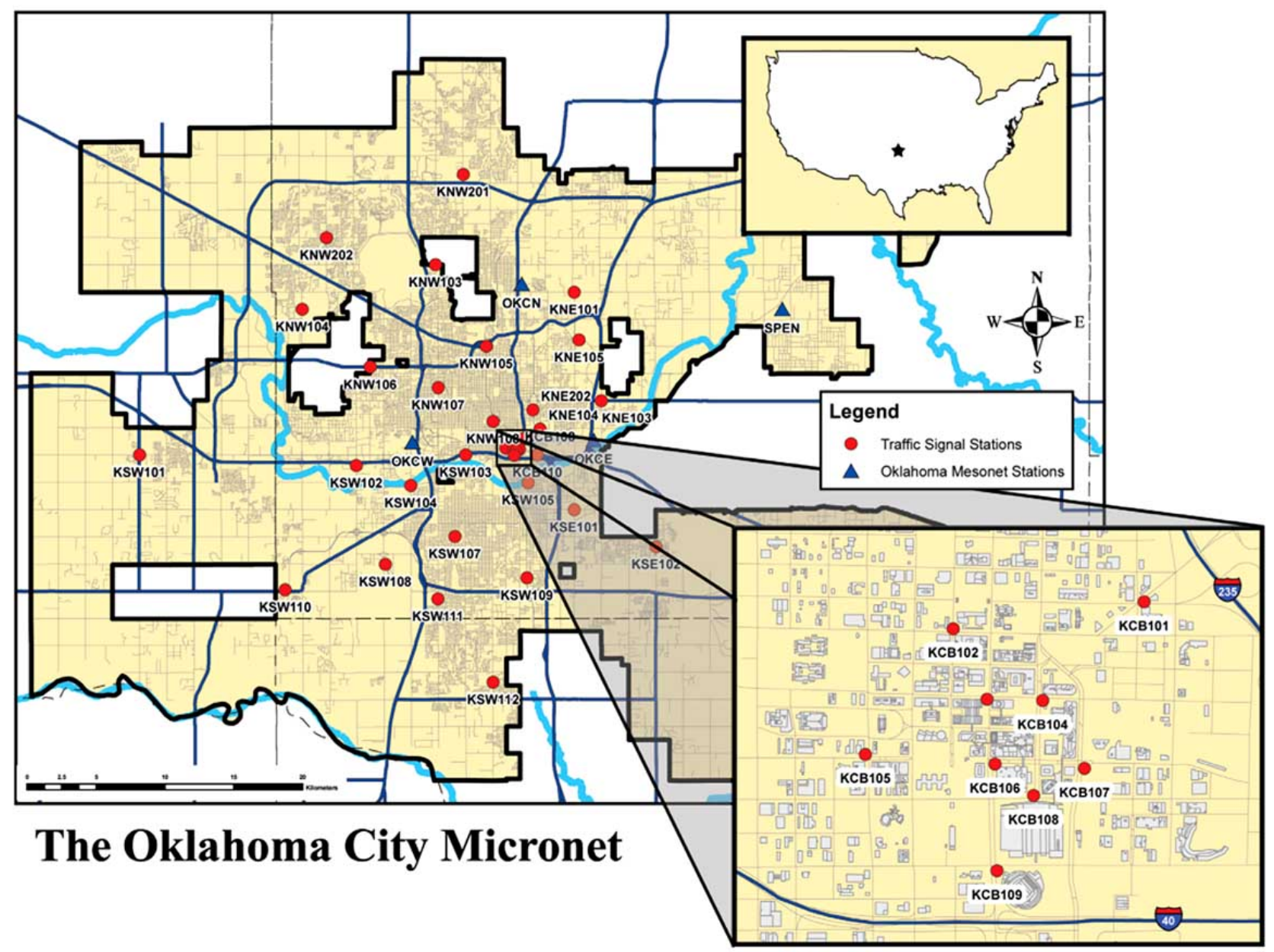

Fig. (1). The distribution of OKCNET sites as of 1 April 2010. 
composition and orientation of buildings greatly affects the urban environment. The Urban Terrain Zone system focused on building contiguity, function, location within the city, building height, construction type, and year built. Special attention was also paid to the following: street pattern, lot configuration, and building placement and density. The Ellefsen methodology was subsequently applied to ten different cities in the United States in the early nineties.

Based, in part, on the prior efforts of Auer and Ellefsen, Oke [31] designed an urban-based climate classification system for the World Meteorological Organization that divided urbanized terrain into seven discrete regions or "urban climate zones". The zones included qualitative descriptions as well as quantitative ranges of roughness length, aspect ratio, and impermeable surface percentage. The concept behind this system was to classify zones based off of their ability to modify the wind, thermal, and moisture properties. More recently, Stewart and Oke [34] presented an expanded classification system that consisted of nineteen "local climate zones". The Stewart and Oke system incorporates not only the city environment, but agricultural and natural environments as well. The zones are separated using their microscale surface properties including surface roughness height, impervious surface fraction, sky view factor, thermal admittance, albedo, and anthropogenic heat flux.
For each classification scheme (i.e. Auer 1978, Ellefsen 1990/91, Oke 2004, and Stewart and Oke 2009), each OKCNET site was individually evaluated using the guidance provided in the published articles. To complete the assessments, the analysis utilized station photos collected during site deployment, aerial photos, satellite imagery, and individual site visits.

\section{RESULTS}

\subsection{Network Classifications}

The urban meteorological classification systems used for this study focus include various parameters and have varying degrees of spatial and temporal detail. For example, Table $\mathbf{1}$ illustrates the variable ranges for the Oke urban climate zones relevant to Oklahoma City from while Table 2 illustrates the critical values that define the Stewart and Oke local climate zones relevant to Oklahoma City. A common thread between the four classification systems is that, in general, conditions within approximately one to two hundred meters were needed to determine the local climate for an OKCNET station.

Table 3 displays the results of the classification analyses when applied to the OKCNET stations. Because data is archived for sites that have been decommissioned or moved, forty-two sites are listed. For the Auer system, the greatest

Table 1. Range of Surface Properties for Associated Urban Climate Zones Used in Oklahoma City [31]

\begin{tabular}{|c|c|c|c|}
\hline Urban Climate Zone & Roughness Class & Aspect Ratio & \% Built (Impermeable) \\
\hline \hline UCZ1 & 8 & $>2$ & $>90$ \\
\hline UCZ2 & 7 & $1.0-2.5$ & $70-95$ \\
\hline UCZ4 & 5 & $0.05-0.2$ & $35-65$ \\
\hline UCZ5 & 6 & $0.1-0.5$ (depend on trees) $<40$ & $<10$ \\
\hline UCZ6 & 5 & $>0.05$ (depends on trees) & \\
\hline UCZ7 & 4 & up to $>1$ with trees) & $<10$ \\
\hline
\end{tabular}

Table 2. Range of Surface Properties for Associated Local Climate Zones Used in Oklahoma City [34]

\begin{tabular}{|c|c|c|c|c|c|c|}
\hline Local Time Zone & $\begin{array}{l}\text { Mean Sky View } \\
\text { Factor }\end{array}$ & \% Built & Roughness Class & Albedo & Thermanl Admittance & $\begin{array}{c}\text { Anthropogenic } \\
\text { Heat Flux }\end{array}$ \\
\hline Modern Core & $0.4-0.6$ & $>90$ & 8 & $0.12-0.2$ & $1200-1500$ & $100-1500$ \\
\hline Old Core & $0.3-0.6$ & $>85$ & 6,7 & $0.15-0.2$ & $1200-2000$ & $30-40$ \\
\hline Extensive Lowrise & $0.8-0.95$ & $>80$ & 5 & $0.15-0.25$ & $1200-1700$ & $30-50$ \\
\hline House and Garden & $\begin{array}{c}0.6-0.9 \\
\text { (depend on trees) }\end{array}$ & $35-70$ & $\begin{array}{c}5,6 \\
\text { (depend on trees) }\end{array}$ & $\begin{array}{c}0.1-0.2 \\
\text { (depend on trees) }\end{array}$ & $500-1200$ & $10-15$ \\
\hline Open Grounds & $0.8-0.9$ & $20-40$ & 5,6 & $\begin{array}{c}0.1-0.2 \\
\text { (depends on moisture) }\end{array}$ & $\begin{array}{c}1000-1800 \\
\text { (depends on moisture) }\end{array}$ & $5-10$ \\
\hline Dispersed Settlement & $>0.8$ & $<30$ & 5,6 & $0.15-0.2$ & $800-1500$ & $<5$ \\
\hline Forest & $0.3-0.5$ & $<10$ & 7,8 & $\begin{array}{c}0.1-0.2 \\
\text { (depends on moisture) }\end{array}$ & $\begin{array}{c}600-2200 \\
\text { (depends on moisture) }\end{array}$ & 0 \\
\hline Grassland & $>0.95$ & $<10$ & $\begin{array}{c}3,6 \\
\text { (depend on trees) }\end{array}$ & $\begin{array}{c}0.1-0.2 \\
\text { (depends on moisture) }\end{array}$ & $\begin{array}{c}600-2200 \\
\text { (depends on moisture) }\end{array}$ & 0 \\
\hline
\end{tabular}


Table 3. Classification of OKCNET Sites

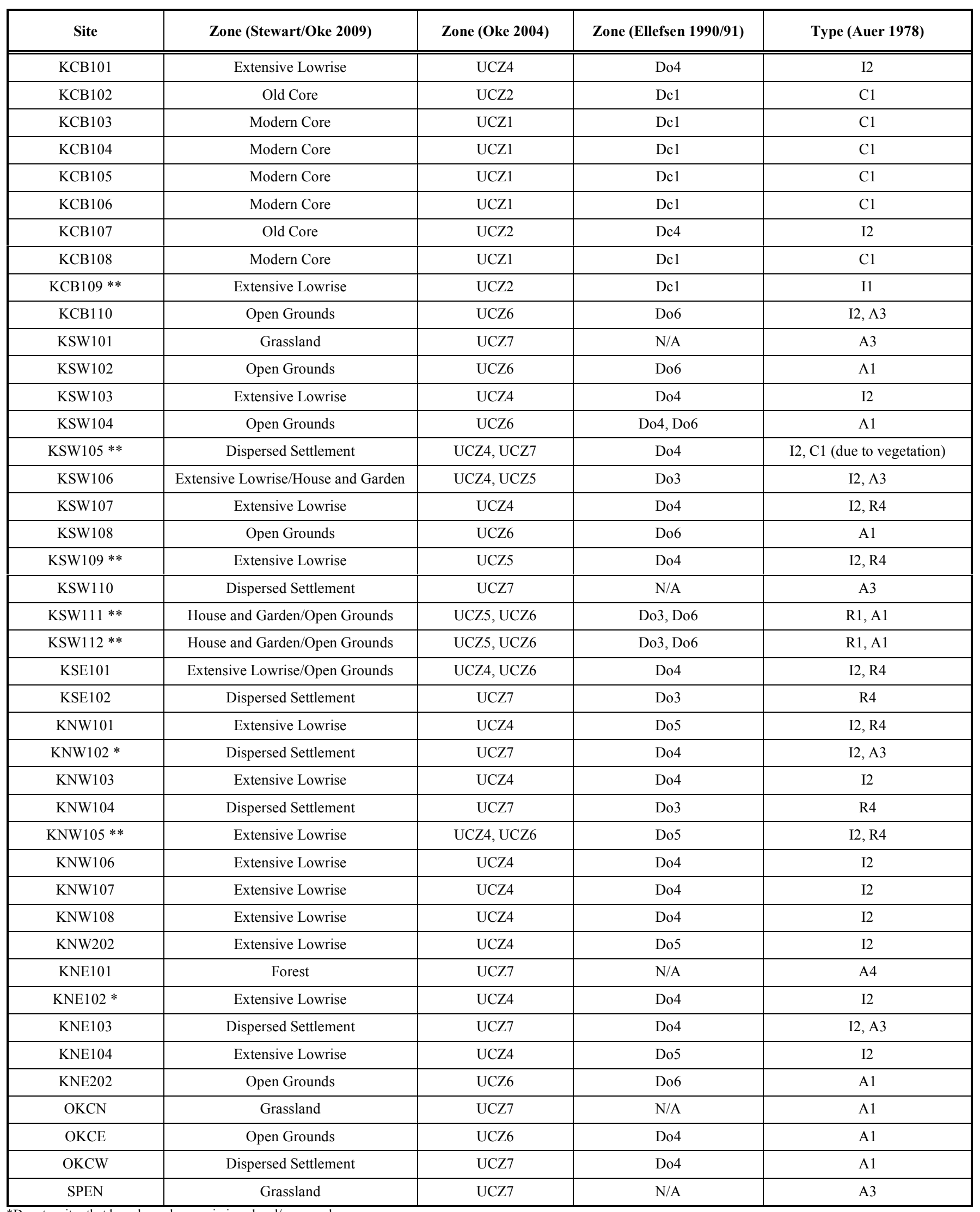


number of sites were classified as $\mathrm{I} 2$, which is best described as conditions including lowrise buildings (approximately 1 to 3 stories tall) having flat roofs and with less than $5 \%$ of the surface occupied by vegetation. The Ellefsen zone Do4 described as detached, open-set, widely distributed buildings with numerous parking lots described the largest number of OKCNET sites. For the Oke system, the highest percentage of OKCNET sites were classified within the UCZ4 zone, which is described by highly developed low or medium density urban development with large horizontal buildings and paved parking. Finally, the Stewart and Oke system classified the largest number of OKCNET sites within the Extensive Lowrise local climate zone. Thus, such sites were deployed in areas that included expanses of flat buildings typically less than 3 stories tall and with numerous paved surfaces.

Overall, many OKCNET sites were categorized with relative ease for each of the classification systems. However, several locations were difficult to classify due to the nature of the local surroundings. For example, the Auer system yielded 21 sites that were difficult to classify and 12 sites that included two different categories in the final results. For the Ellefsen system, 16 sites were difficult to classify with 3 sites classified using two different zones. However, the Ellefsen system also yielded 5 sites that could not be classified at all due to a lack of buildings near the sites. The Oke system included 7 sites that were a challenge to classify and 6 of those sites had to be classified with two zones, while the Stewart and Oke system yielded 9 challenging sites with only 4 of the sites classified using two different zones.

\subsection{Traffic Signal Site Examples}

Six traffic signal sites proved difficult to classify using all four systems (marked with two asterisks in Table 3). The land use in varying quadrants adjacent to the local traffic intersections created the classification challenge. For example, site KNW105, located in the north-central portion of the Oklahoma City metropolitan area, followed the I2, Do4, UCZ4, and Extensive Lowrise zones for approximately $75 \%$ of the surrounding conditions. However, the southwest quadrant includes extensive natural vegetation, including numerous large trees (Fig. 2a-d), which is more consistent with a Do6, UCZ6, and Open Grounds urban setting. Similarly, KCB109, located near the Ford Center arena, south of the central business district, includes the Oklahoma City Botanical Gardens within the northwest quadrant (Fig. 3a-d). Thus, as with KNW105, the characteristics in three quadrants surrounding KCB109 were consistent with one classification, based primarily on the number and density of buildings, while one quadrant yielded much different conditions due to extensive urban vegetation.

The KSW109 site is another example of a location that was difficult to classify into a single zone. The conditions near the location are dominated primarily by lowrise (a)

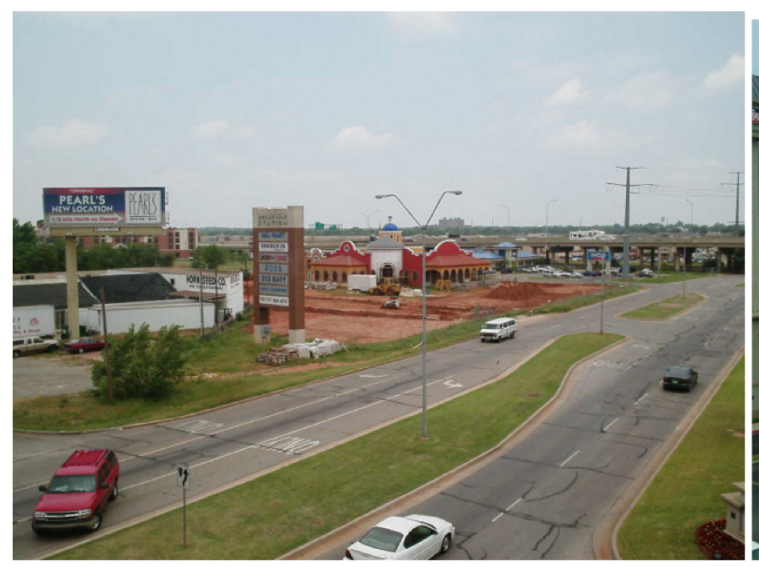

(c)

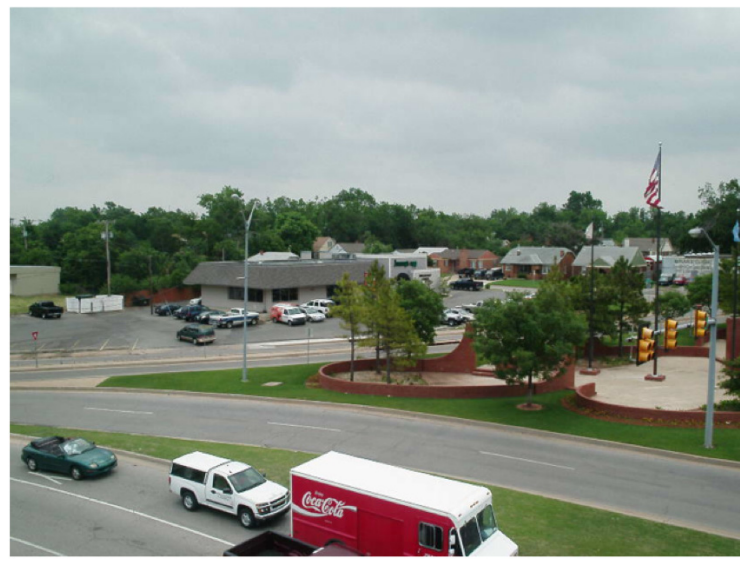

(b)

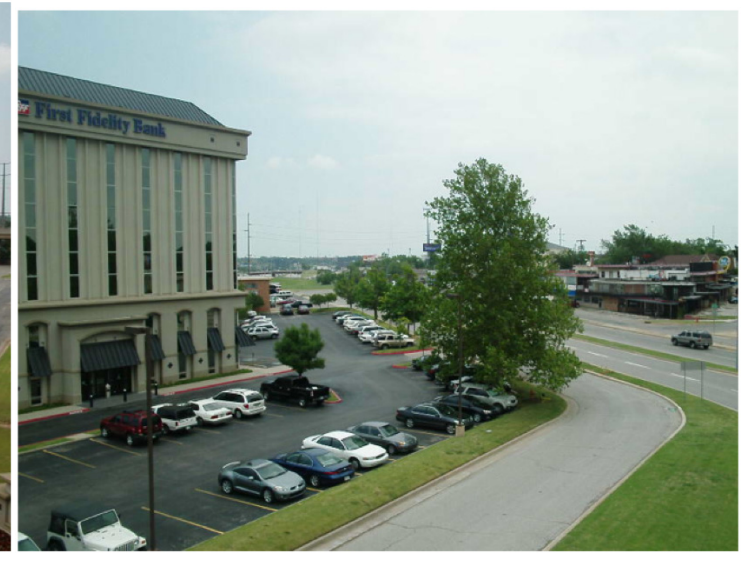

(d)

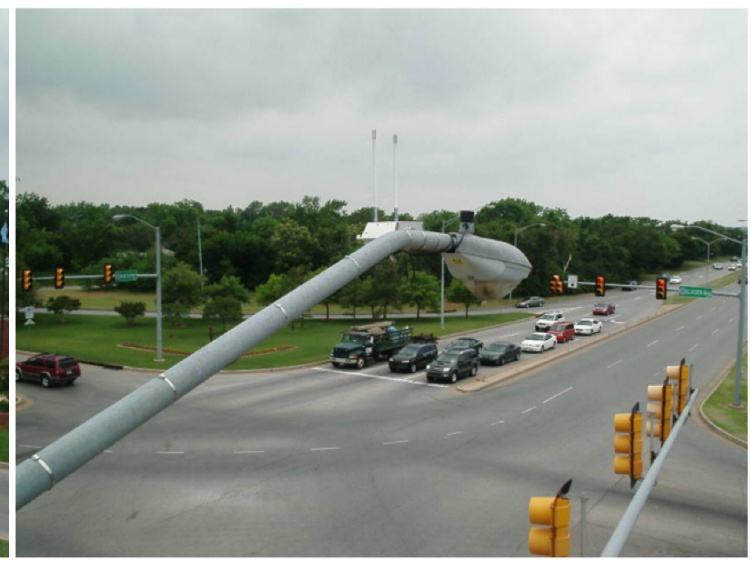

Fig. (2). Site photos for KNW105 looking (a) northwest, (b) northeast, (c) southeast, and (d) southwest. 
(a)

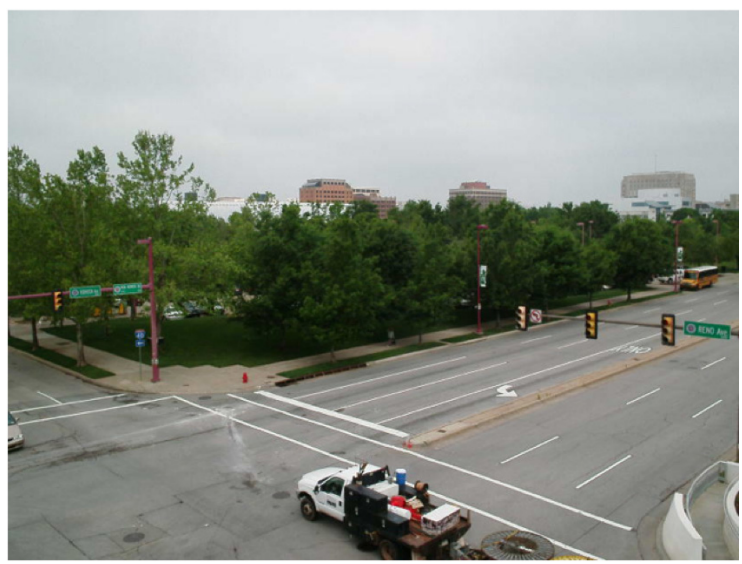

(c)

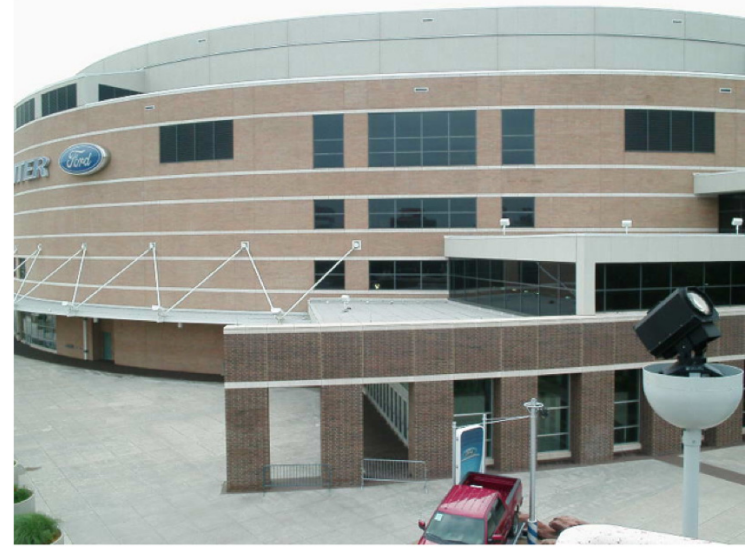

(b)

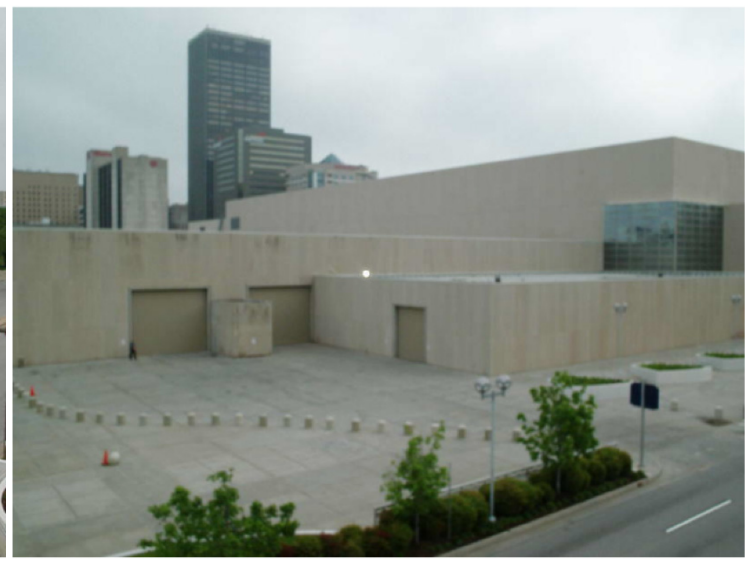

(d)

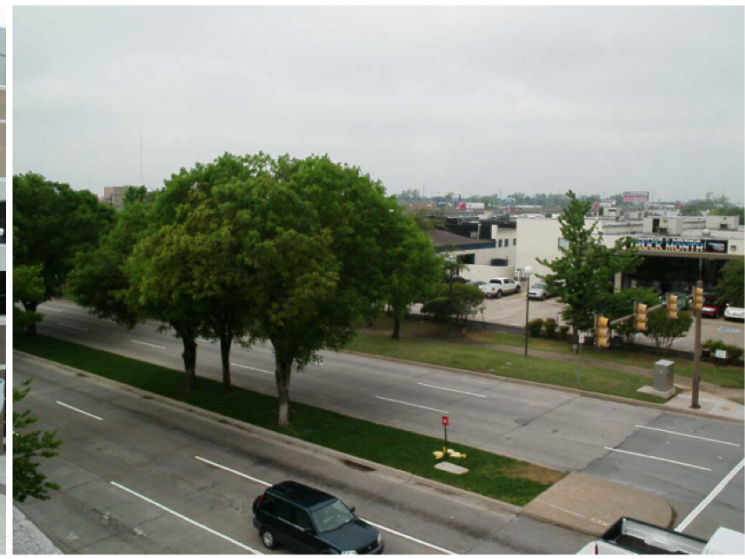

Fig. (3). Site photos for KCB109 looking (a) northwest, (b) northeast, (c) southeast, and (d) southwest.

structures. However, dispersed within the surrounding conditions are numerous vegetative patches, and the southwest corner of the intersection includes a vast open field (Fig. 4a-d). The KSW109 site was classified the same as KNW105 and KCB109 but further demonstrates the complexity created by extensive urban vegetation near the stations which alter the local climate versus other I2, Do4, UCZ4, and Extensive Lowrise sites.

The classification of KSW105 posed other challenges, as streets near the site are wide with moderate traffic, lowrise buildings, and a railroad located nearby. As such, the site would be classified as I2, Do4, UCZ4, and Extensive Lowrise for the respective systems. However, the Canadian River is also located within approximately $100 \mathrm{~m}$ of the site and at least $50 \%$ of the surface near the site is covered by natural vegetation (Fig. 5a-d). As such, this location was classified as Dispersed Settlement using the Stewart and Oke system. The location does meet the criteria of the category, but the anthropogenic heat flux values for the location exceed those associated with a Dispersed Settlement zone. The site was further classified using the UCZ4 and UCZ7 zones using the Oke system, Do4 for the Ellefsen system, and $\mathrm{I} 2$ and $\mathrm{C} 1$ for the Auer system. The reason the $\mathrm{C} 1$ type was added for this site from the Auer system was due to the vegetative cover near the site.

The final two traffic light sites, KSW111 (Fig. 6a-d) and KSW112 (Fig. 7a-d), were difficult to classify because approximately half of the local climate is consistent with land use conditions characterized by a campus setting while the other half is dominated by a residential setting. Thus, each of these sites is equally consistent with the respective classifications of R1, Do3, UCZ5, and House and Garden as well as the A1, Do6, UCZ6, and Open Grounds classifications.

\subsection{Mesonet Site Examples}

Initially, the three Mesonet sites deployed as part of OKCNET (OKCN, OKCW, OKCE) were classified as A1 for the Auer system, unclassified for Ellefsen, UCZ7 for Oke, and Open Grounds for Stewart and Oke. However, after site visits, the site classifications were altered. For OKCN, the Stewart and Oke zone was changed to Grasslands because the local surface characteristics within approximately $200 \mathrm{~m}$ consisted of nearly $100 \%$ natural vegetation. However, just beyond the $200 \mathrm{~m}$ radius, a significant freeway and residential area exists to the west, and a large building complex is located to the north (Fig. 8ad). Thus, while the site is classified based on local characteristics, it is likely that the heterogeneity of the land surface conditions nearby plays a critical role in the local micrometeorology that is not well represented by the classification of the site. Further, due to prevailing southerly wind conditions, the site is typically located downwind of the central business district and experiences the advection of 
(a)

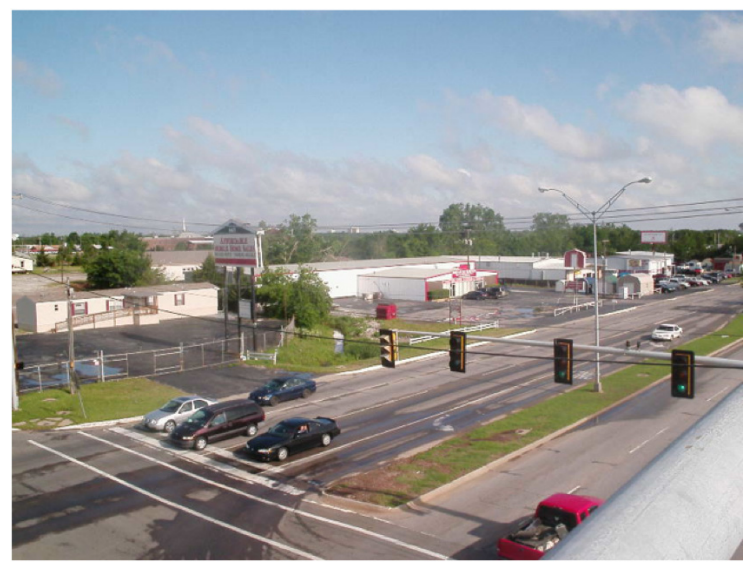

(c)

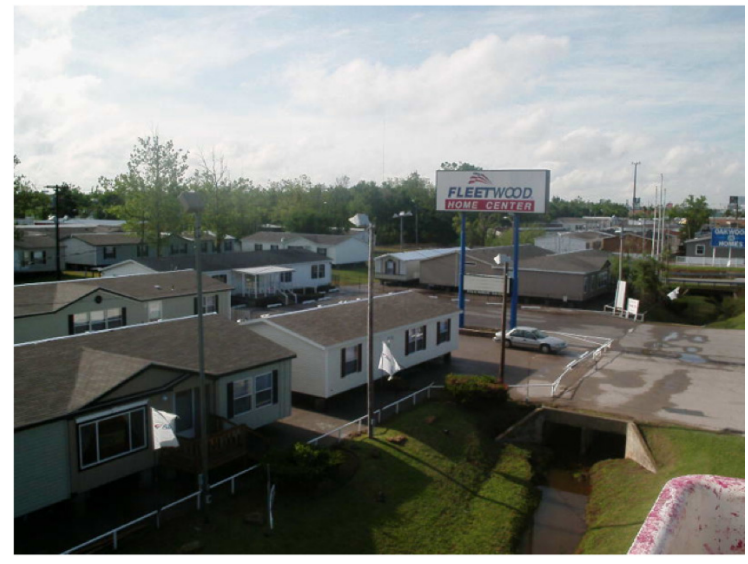

(b)

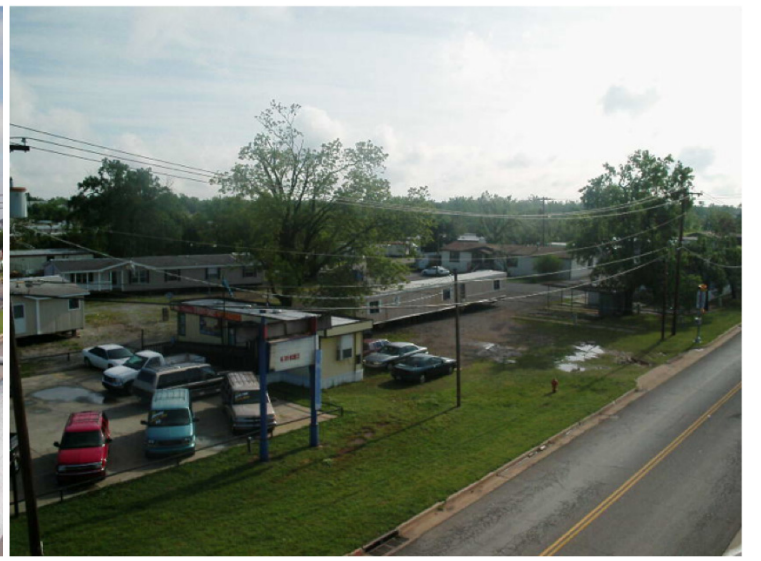

(d)

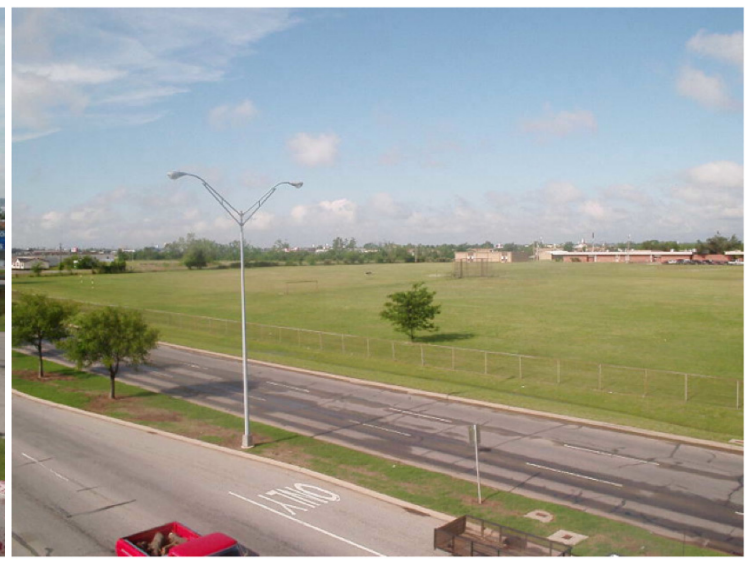

Fig. (4). Site photos for KSW109 looking (a) northwest, (b) northeast, (c) southeast, and (d) southwest.

atmospheric properties from regions not associated with the local microclimate.

The OKCW site (Fig. 9a-d) is located on the campus of Oklahoma State University in Oklahoma City (OSU-OKC) and includes some very unique surface characteristics near the site. For example, a set of railroad tracks is located to the north of the site, an interstate highway is located to the east, and a major thoroughfare is located to the west. Conversely, because the OSU-OKC campus specializes in horticulture, a small section of irrigated crops is located to the south of the site and a small orchard is located to the southeast. Thus, because of the vegetation and the proximity of the roadways, railroad, and buildings, OKCW was reclassified as A1, Do4, UCZ7, and Dispersed Settlement.

Finally, the OKCE site (Fig. 10a-d) is located near an interstate roadway with a small area of lowrise buildings located to the east. In addition, a street is located to the south of the site with a large area of natural vegetation between the site and the road while a city park lies north of the site. After a site visitation, OKCE was reclassified as A1, Do4, UCZ6, and Open Grounds.

\section{DISCUSSION}

This study and the associated results are important as it illustrates that while a need exists for increased metadata from meteorological stations in urban areas, classifying such sites is difficult due to the heterogeneity of surface conditions in cities which alter the behavior of local climates. Currently, a universal urban classification system is not in place for urban meteorological stations and this study focused on developing a through metadata dataset for OKCNET using four existing systems.

The number of sites easily classified was dependent upon which system was used. For the Auer [33] system, the range of vegetation was limited, which yielded extensive challenges when classifying the OKCNET sites. Previous studies have demonstrated vegetative cover within the urban environment to be a significant contributor to the local energy balance and microclimate $[6,19,23,41]$, and as such, vegetation requires significant emphasis when developing a site classification system. The Urban Terrain Zone system presented by Ellefsen [30] was an overall improvement over the Auer [33] classification system due to increased details focused on structures within urban areas. However, for sites with little to no structural features, the system failed because it is based solely on building characteristics. The Oke [31] system represents vast improvement over Auer [33] and Ellefsen [30] because of the inclusion of specific quantitative values that serve as guidance for the classification of a site, while the Stewart and Oke [34] system further expanded the 
(a)

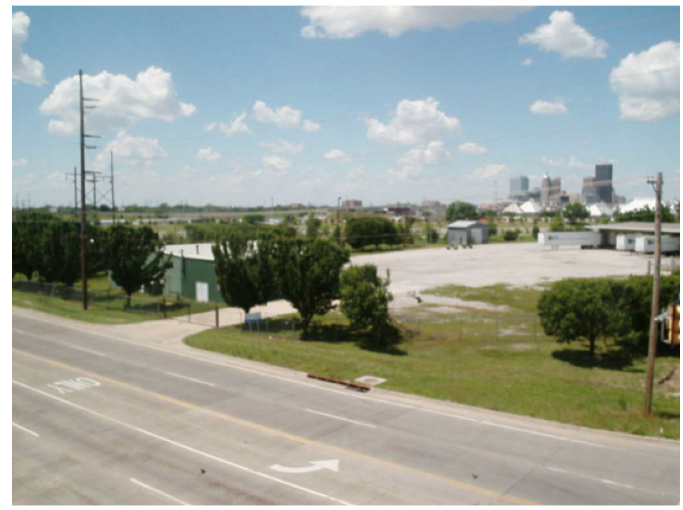

(c)

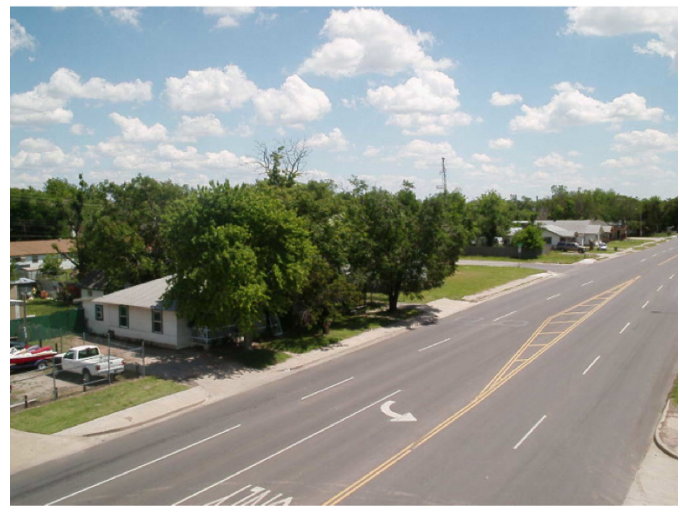

(b)

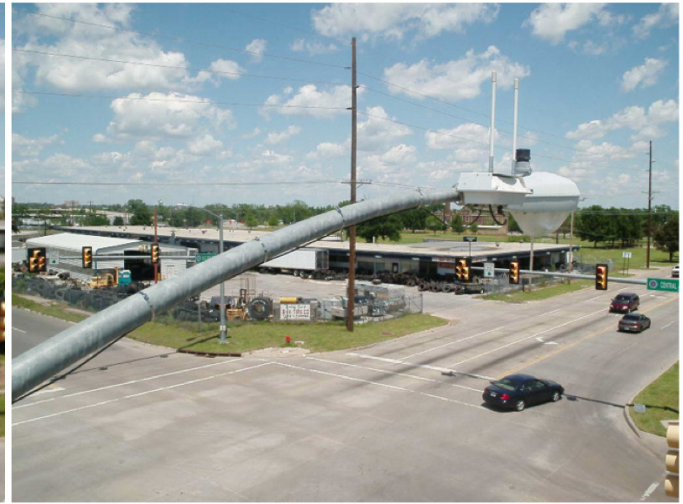

(d)

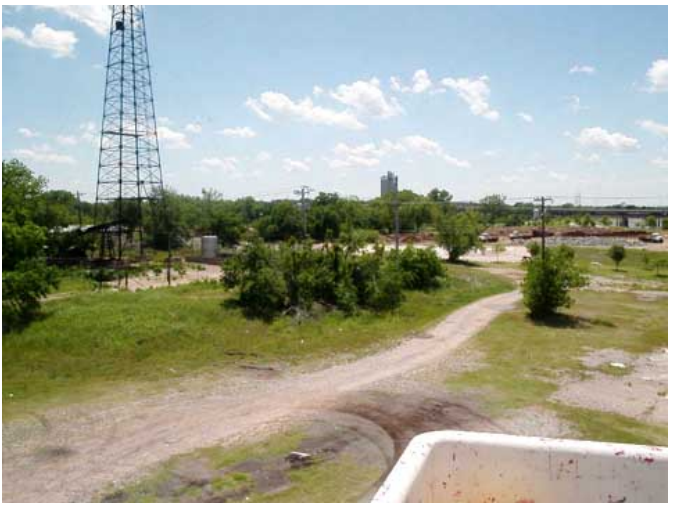

Fig. (5). Site photos for KSW105 looking (a) northwest, (b) northeast, (c) southeast, and (d) southwest.

(a)

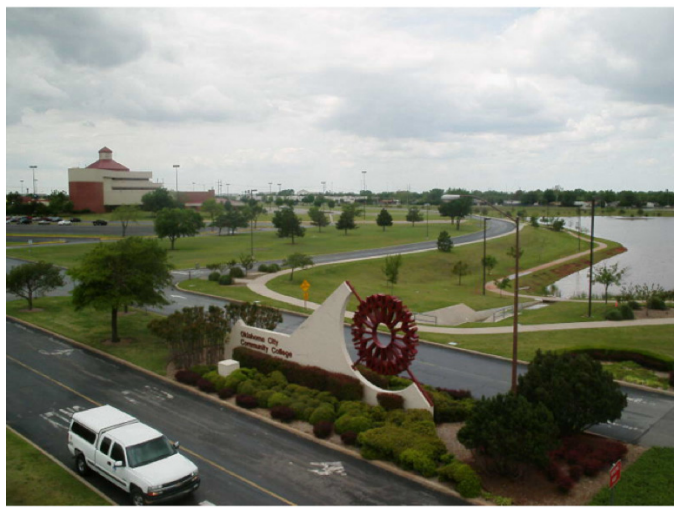

(c)

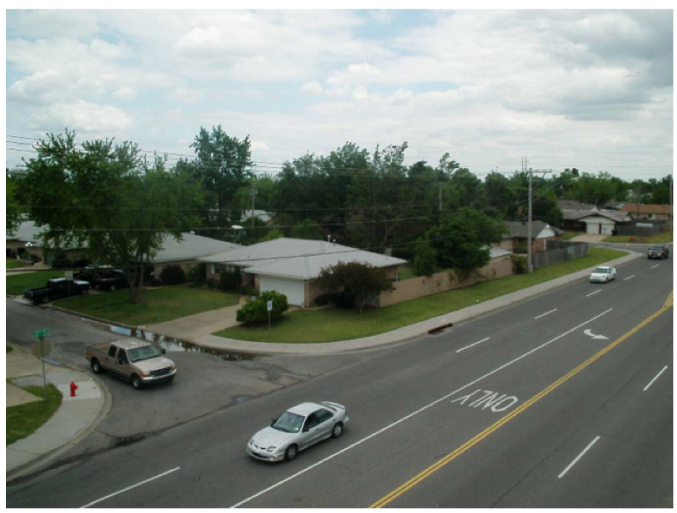

(b)

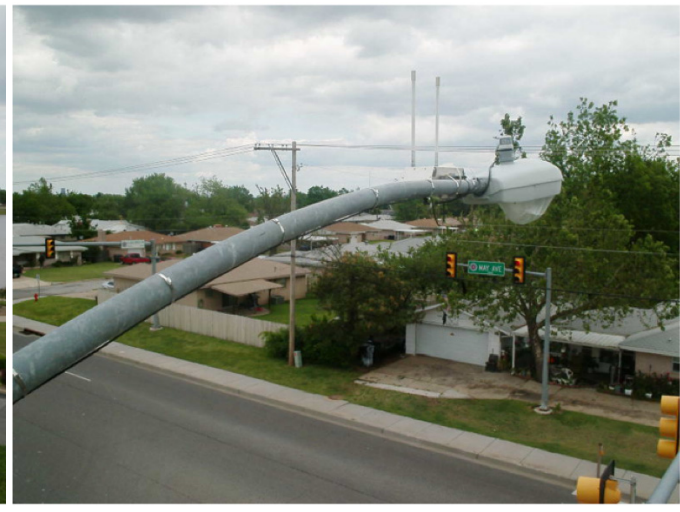

(d)

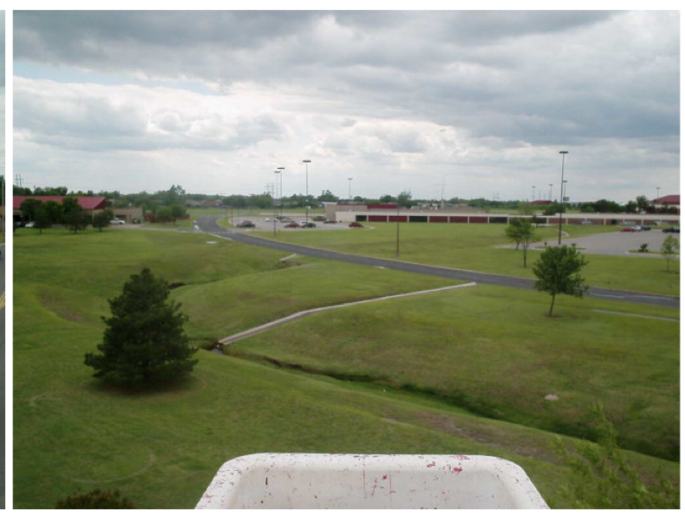

Fig. (6). Site photos for KSW111 looking (a) northwest, (b) northeast, (c) southeast, and (d) southwest. 
(a)

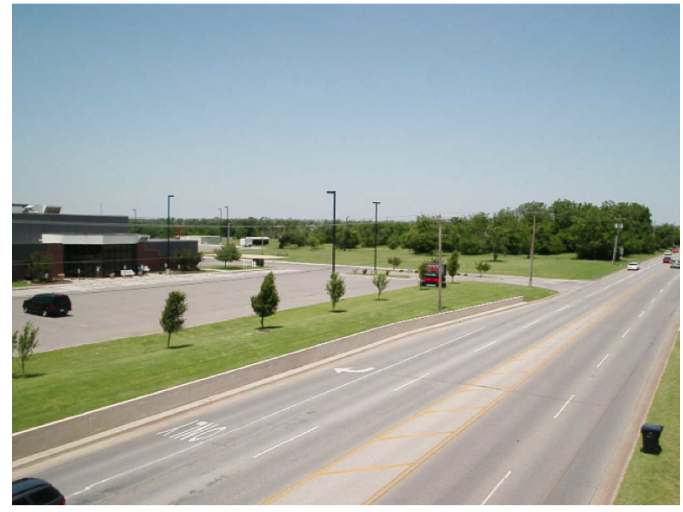

(c)

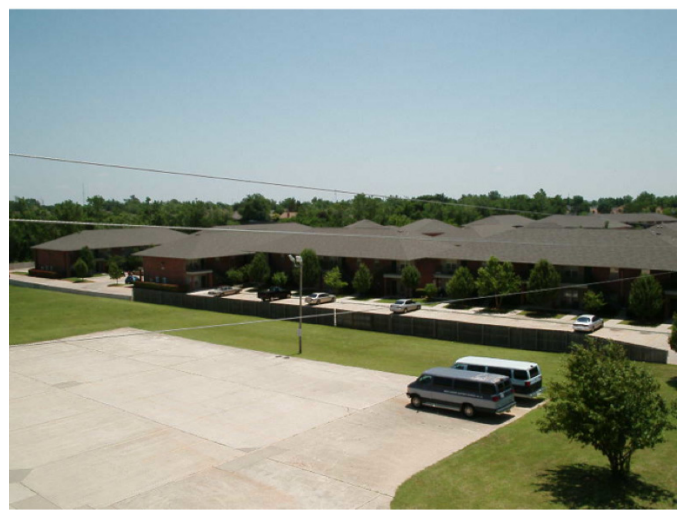

(b)

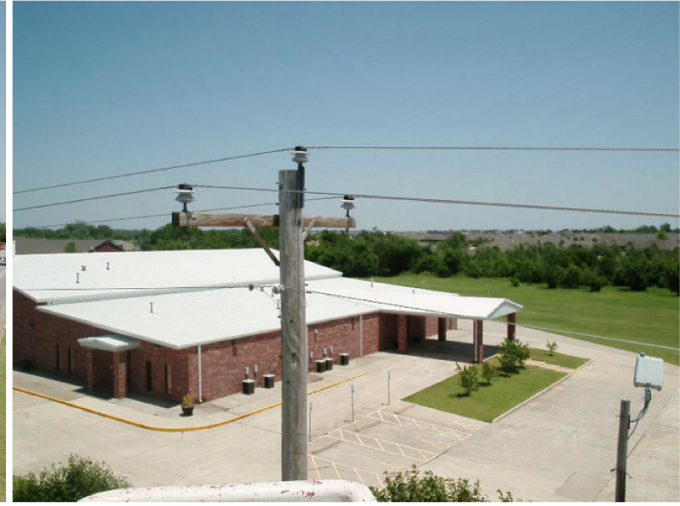

(d)

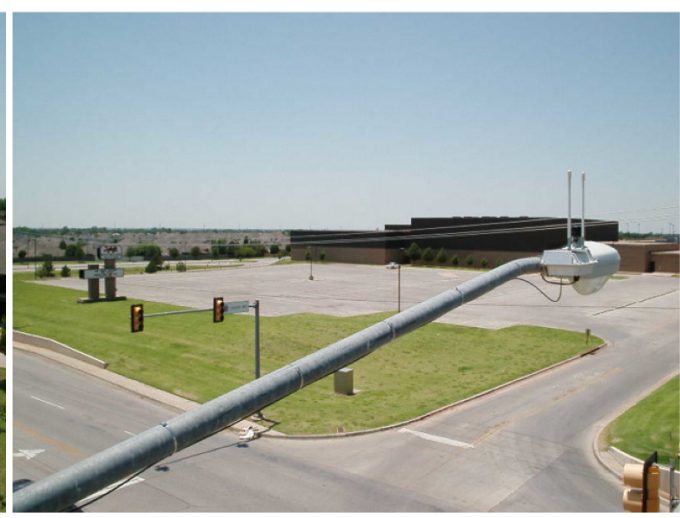

Fig. (7). Site photos for KSW112 looking (a) northwest, (b) northeast, (c) southeast, and (d) southwest.

(a)

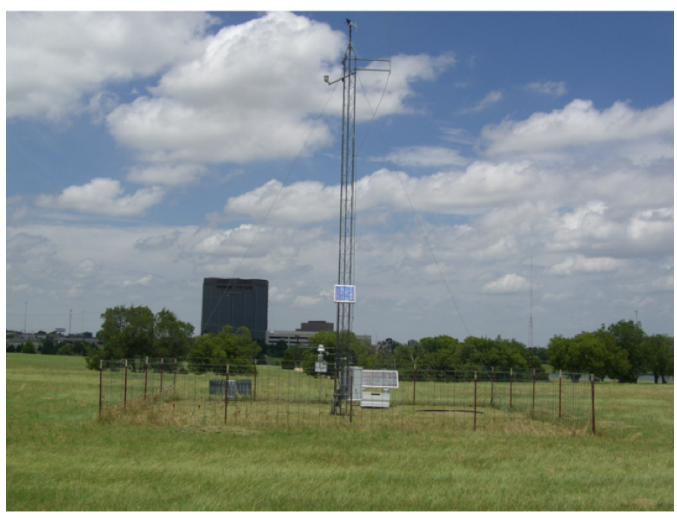

(c)

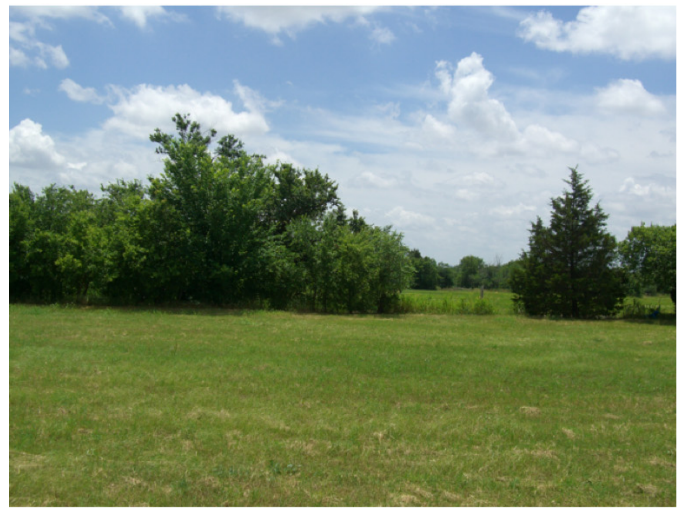

(b)

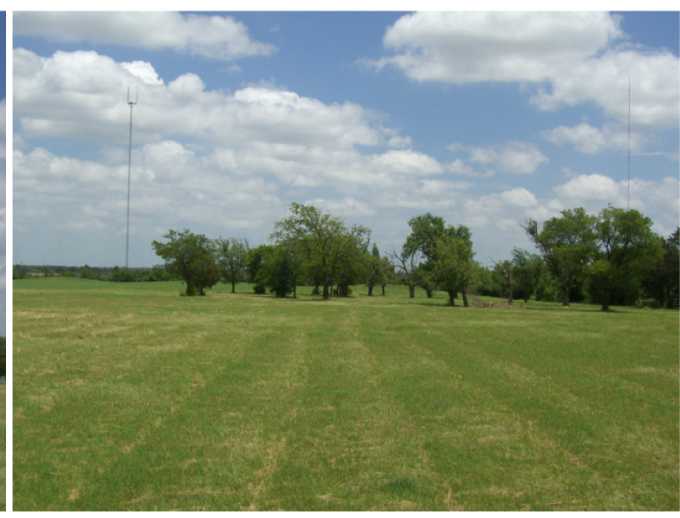

(d)

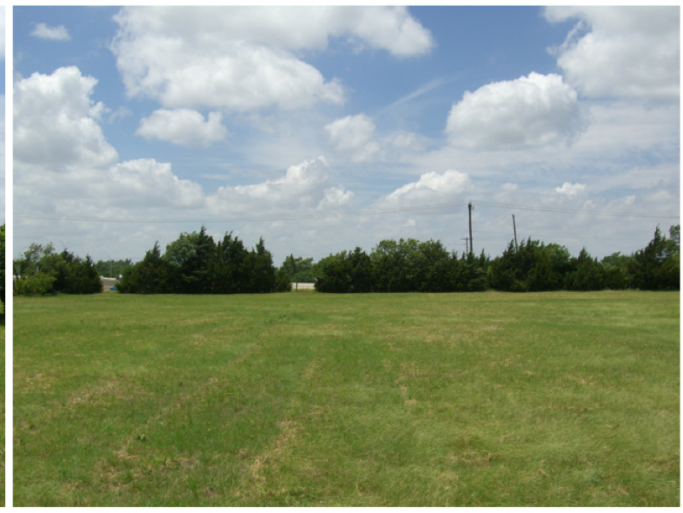

Fig. (8). Site photos for OKCN looking (a) north, (b) east, (c) south, and (d) west. 
(a)

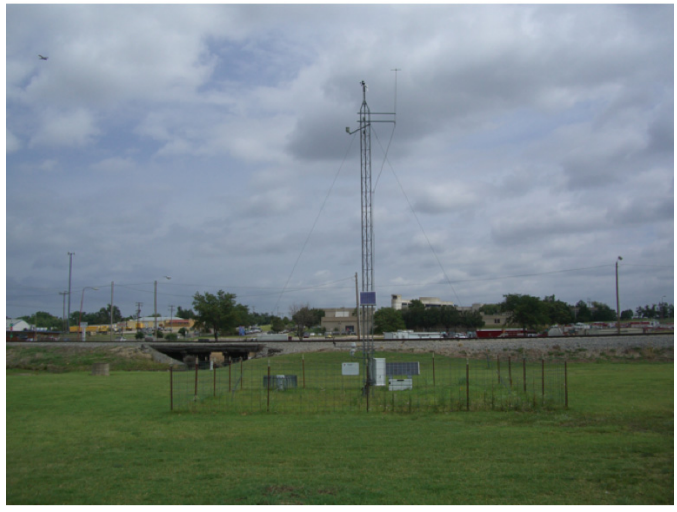

(c)

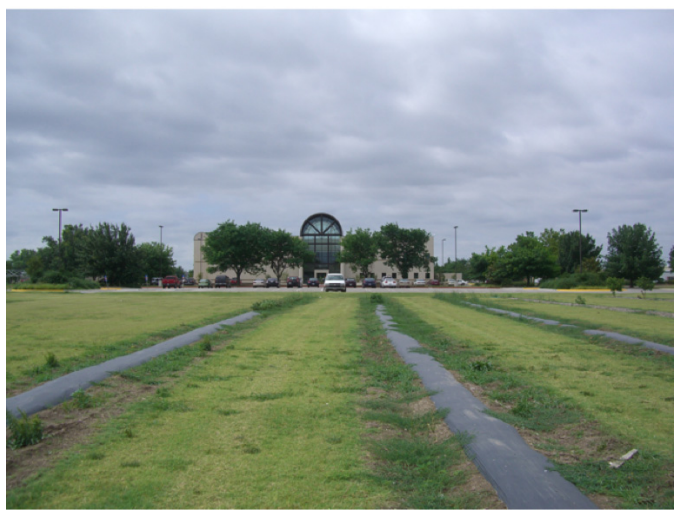

(b)

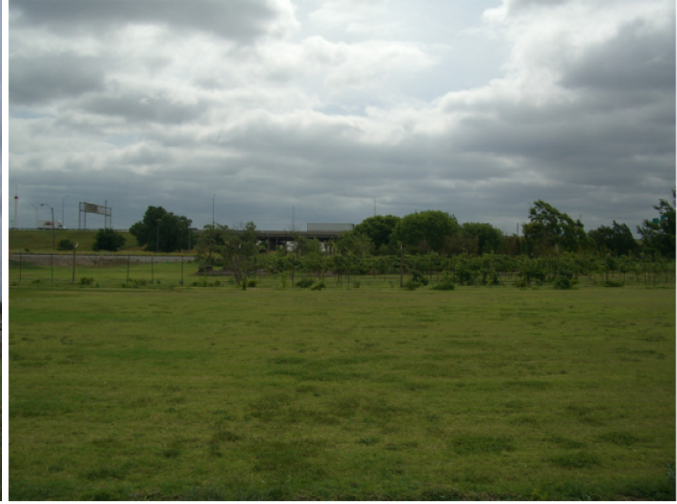

(d)

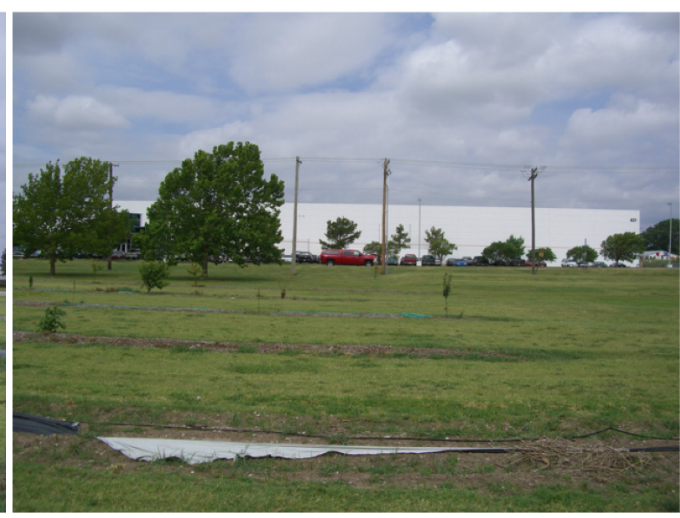

Fig. (9). Site photos for OKCW looking (a) north, (b) east, (c) south, and (d) west.

(a)

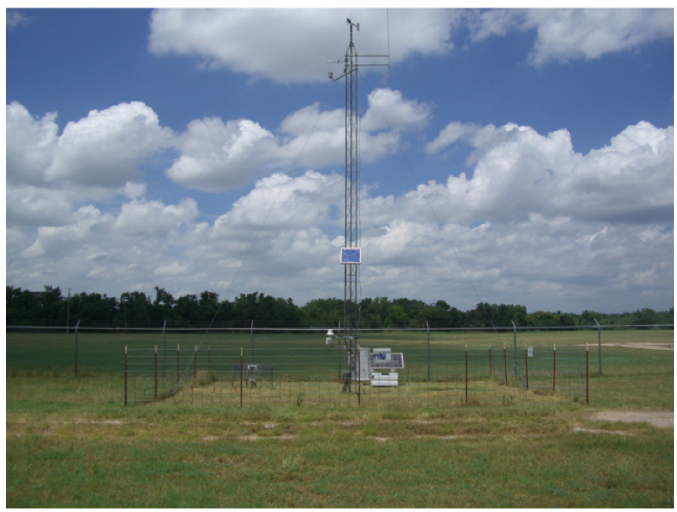

(c)

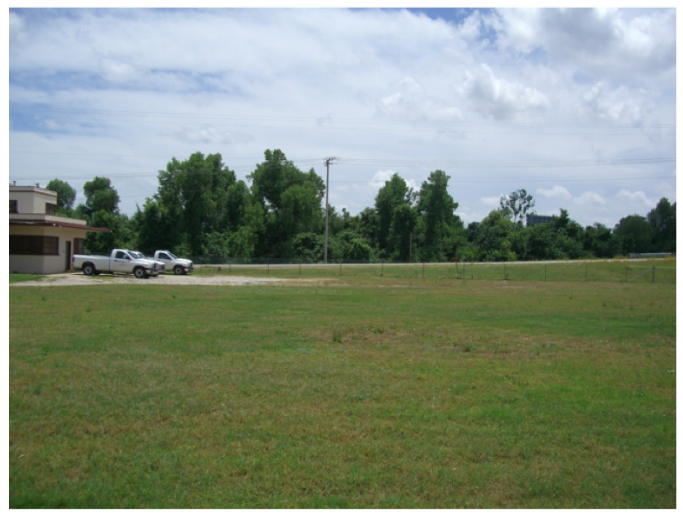

(b)

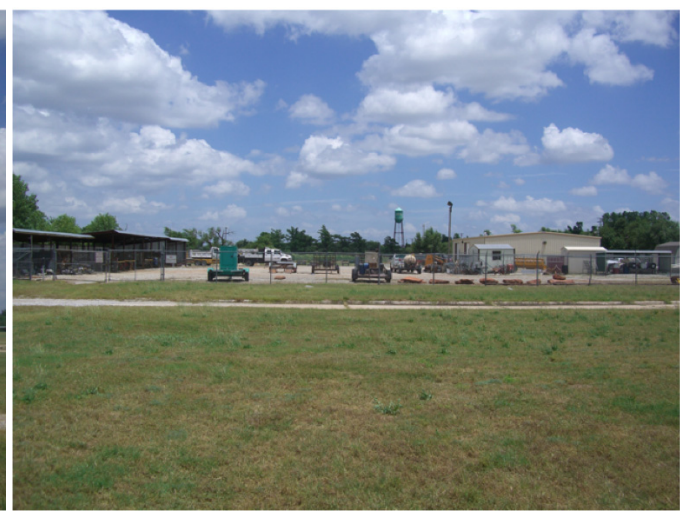

(d)

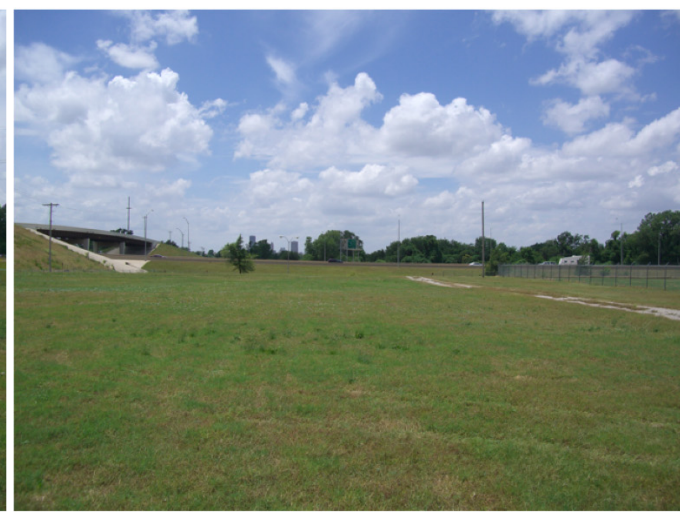

Fig. (10). Site photos for OKCE looking (a) north, (b) east, (c) south, and (d) west. 
quantitative structure to specific, neighborhood-scale characteristics. Even so, while the Stewart and Oke [34] system yielded fewer sites that required multiple zone assignments versus the other classification systems, challenges still existed in classifying certain sites using such specific categories.

The main obstacle in classifying OKCNET sites occurred in the transition zones of land cover and land use. This was especially true within the transition from suburban to rural whereby increased vegetation is interspersed with structures and impermeable surfaces. Additionally, in the transition zone from suburban to urban, large expanses of impermeable surface exist for parking that do not include structures but may include vegetation. Such conditions are not easily classified by any of the current systems yet are critical to the local microclimate.

It should also be noted that Oklahoma City is a relatively young metropolitan area. Founded in 1889, Oklahoma City is a rapidly growing urban area and since the 2000 United States Census, the population of the Oklahoma City Metropolitan area has increased by an estimated $10.1 \%$ to a total exceeding 1.2 million residents [42]. Currently, the Oklahoma City metropolitan area ranks as the $31^{\text {st }}$ most populated urban area in the United States. At the same time, the spatial domain of the municipal boundaries of Oklahoma City have grown to span nearly $1610 \mathrm{~km}^{2}$ which places Oklahoma City within the top ten largest cities by land area in the United States, and the largest city that is not a consolidated city-county. However, the portion of Oklahoma City that is currently urbanized is considerably less (approximately $630 \mathrm{~km}^{2}$ ).

The design of Oklahoma City contributed to a number of unique site classification issues. Because the vast majority of streets are aligned along a grid (i.e., regularly spaced northsouth and east-west oriented streets), conditions near the traffic signal sites typically consisted of "quadrants". In a number of cases (e.g., KNW105, KCB109, etc.) one or more quadrants included surface conditions dramatically different from those in adjacent quadrants. This demonstrates that overall urban design of a city (in this case the street orientation) can play a role in the challenges associated with classifying the stations in addition to the overall local microclimate of an area.

The OKCNET example also illustrates a potentially critical component that is generally lacking from the classification systems. In general, the ambient wind speed values at $10 \mathrm{~m}$ in central Oklahoma exceed $5 \mathrm{~ms}^{-1}$, even during the nocturnal period. Thus, conditions upstream of a site can play an important role in the meteorological values observed at a given location. Because the four classification systems employed during this study focused on the local conditions (i.e., 100-200 $\mathrm{m}$ near the site), processes due to fetch such as thermal advection are not adequately considered. Yet, those sites downwind of the central business district often display characteristics associated with the advection of the urban heat island demonstrating that advection from regions beyond the microclimate environment, yet still within the local urban environment, should be considered in future classification systems.
To demonstrate the importance of thermal advection to atmospheric processes in urban areas, two examples of the urban heat island of Oklahoma City are presented in Fig. (11a, b). The first (Fig. 11a) represents the classic urban heat island signature that occurs at night during clear, calm conditions. As such, the warmest temperature conditions were located in and around the central business district of Oklahoma City and decreased through the suburban zones to minimum values in the rural areas. In such conditions, the local surface characteristics (i.e., 100-200 m near the site) play a critical role in modulating the thermal properties at the location of the measurement. Thus, the urban meteorological classification systems evaluated in this study would be more likely to sufficiently describe relevant atmospheric processes given their focus on the local surface properties.

However, the second example (Fig. 11b) represents the urban heat island in Oklahoma City during southerly wind conditions (approximately $5 \mathrm{~ms}^{-1}$ ). As a result, the urban heat island resembled a plume with the core of warmest air located north of the central business district due to thermal advection from the central business district. As such, the OKCN Mesonet site shown in Fig. (10) was actually warmer than those locations in the central business district due to (1) the downwind displacement of the thermal anomaly and (2) the advection of relatively cooler air from the suburbs into the central business district. This scenario, which is climatologically more likely given the general absence of calm nocturnal conditions in central Oklahoma, yields measurements collected at the sites significantly impacted by upstream properties. Thus, fetch becomes increasingly important and the local characteristics, which still play a role, decrease in importance.

Finally, while Oklahoma City currently includes approximately $630 \mathrm{~km}^{2}$ of urbanized area, future urbanization is very likely given the available terrain within its municipal boundaries. The increased urbanization is especially critical within the transition zone from rural to suburban and will likely impact the classification of OKCNET stations in the future. For example, after viewing the site photos for KSW101 and conducting a site visit, the location was classified as A3, UCZ7, and Grassland given the overall rural, agricultural surface conditions (not shown). However, in the distance new development exists and while the local climate consisted of at least $80 \%$ untouched natural vegetation, revisiting this site will be crucial as the surface conditions transition from rural to suburban in the next few years. Thus, the example of KSW101 demonstrates that while the classification of truly rural sites away from cities many not change for decades, within the urban environment, changes to the surface conditions can occur relatively quickly. As such, the collection of regular metadata such as site photos is essential to further update the classification of urban meteorological sites as needed.

\section{CONCLUSION}

Following the deployment of OKCNET, the collection of station metadata was identified as a critical need to support the operations of the network and associated scientific research. This study illustrates not only the need for increased metadata from urban meteorological stations but also the challenges associated with classifying urban sites 
(a)

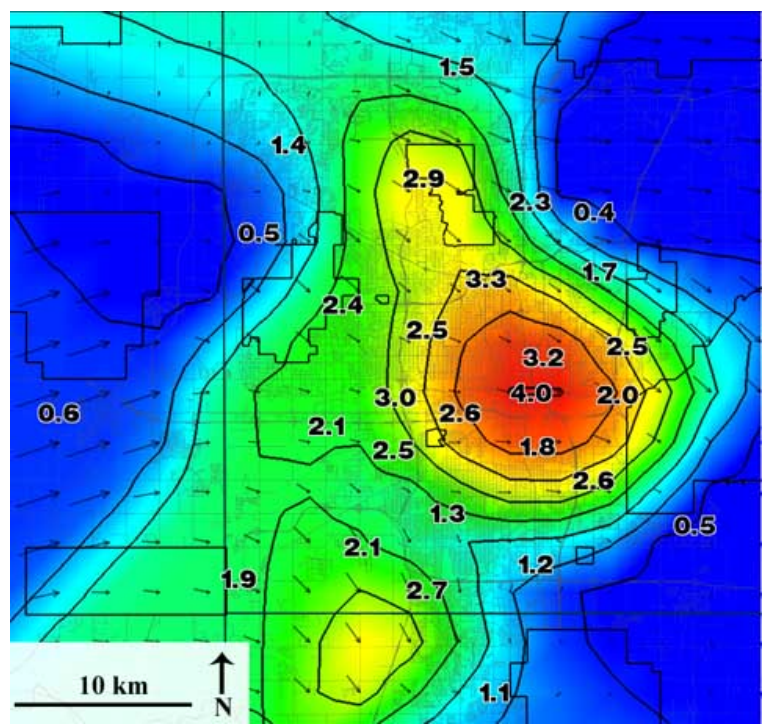

(b)

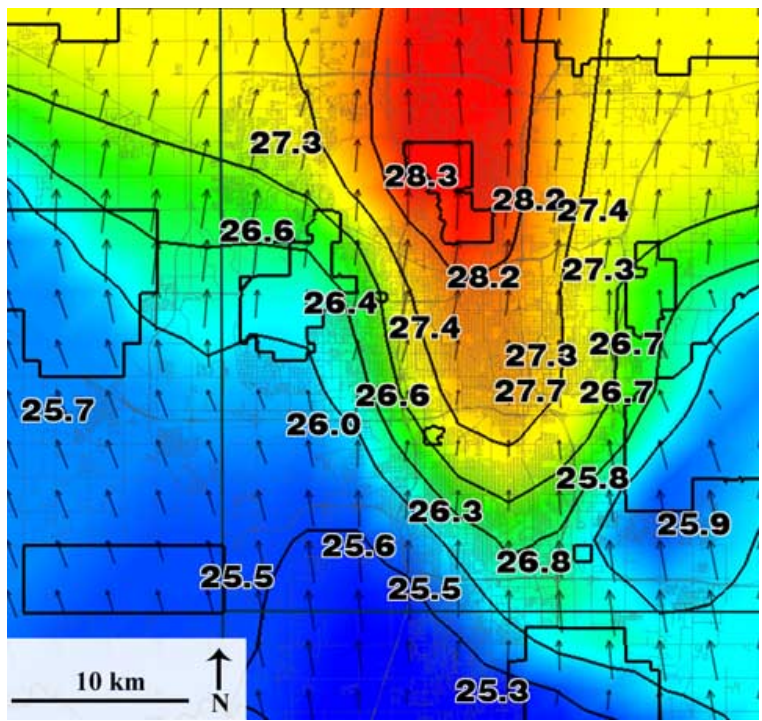

Fig. (11). Observations of the urban heat island in Oklahoma City on (a) 26 November 2009 at 1054 UTC and (b) 27 June 2009 at 1052 UTC. The observations include 9-m air temperature at OKCNET traffic signal stations and Oklahoma Mesonet stations along with interpolated air temperature (black contours every $1^{\circ} \mathrm{C}$ ) and wind vectors. Color shading has also been added to enhance the visibility of the air temperature gradient.

using existing methodologies due to (1) the heterogeneity of the surface and (2) limitations associated with the methodologies. Thus, the number of OKCNET sites easily classified was dependent upon individual site surface characteristics and the classification system used.

The main obstacle in classifying OKCNET sites occurred in the transition zones of land cover and land use (i.e., rural to suburban and suburban to urban) demonstrating that a need exists for future studies that address the classification of meteorological sites specifically in locations that include the greatest heterogeneity of surface conditions. At the same time, the overall design of Oklahoma City and placement of OKCNET traffic signal sites at the intersections of streets also yielded increased complexity in and around the stations that contributed to difficulty in establishing consistent metadata from site to site and classification system to classification system. As such, this study further demonstrates that the unique characteristics of individual cities as well as the placement of meteorological stations should be carefully considered when deploying an operational network. Further, each of the classification methodologies used in this analysis focused primarily on the local microclimate within 100-200 $\mathrm{m}$ of the location. However, in cities such as Oklahoma City where wind speed conditions consistently exceed $5 \mathrm{~ms}^{-1}$ or greater (even during the nocturnal period) additional emphasis should be placed on the larger-scale surroundings as well as fetch to quantify the role of advection.

Thus, given the results of this analysis, the following recommendations for future urban meteorological classification systems should incorporate:

- qualitative classes and quantitative ranges of particular surface characteristics including surface albedo, roughness, thermal admittance, mean sky view factor, the percentage of impermeable surfaces, estimates of anthropogenic heat flux, etc.;

- the percentage of vegetative cover and vegetation type;

- building and development structure; and

- the atmospheric fetch that influences the observations at each site for varying wind speed and direction.

Each of the urban site classification schemes utilized for this study included at least one of the recommendations. However, none of the systems incorporated all in a manner that provided a straightforward classification of all sites deployed as part of OKCNET, and yet, the recommendations provide essential information needed to gain a qualitative and quantitative understanding of the local processes that may impact the data collected at the meteorological stations.

It should also be noted that, as part of the deployment of urban meteorological sites or networks, it is critically important to collect the corresponding metadata consistent with the aforementioned recommendations. Finally, due to the ever-changing urban landscape and associated development, the metadata should be collected at regular intervals during routine maintenance to record changes in the characteristics near the associated sites. Such information is vital to anyone not directly associated with the sites and data to (a) gain knowledge of the local site characteristics and (b) how those characteristics have evolved with time.

\section{ACKNOWLEDGEMENTS}

Funding for the Oklahoma City Micronet and support for this study was provided by (1) the State of Oklahoma via a capital bond issue to improve facilities at the University of Oklahoma and (2) the Office of the Vice President for Research at the University of Oklahoma. The Oklahoma Mesonet is supported by Oklahoma taxpayers who fund the 
Mesonet through the Oklahoma State Regents for Higher Education. A special thanks is needed for the Southern Climate Impact Planning Program (SCIPP) for providing funding for this research. The authors would also like to thank Dr. Petra Klein for her inspiration of this study, Phil Browder for the collection of the traffic signal site photos, and Ian Stewart and Dr. Tim Oke for assistance related to their 2009 classification system.

\section{REFERENCES}

[1] Changnon SA. Inadvertent weather modification in urban areas: Lessons for global climate change. Bull Am Meteor Soc 1992; 73(5): 619-27.

[2] Grimmond CSB, Oke TR. Aerodynamic properties of urban areas derived from analysis of surface form. J Appl Meteor 1999; 38(9): 1262-92.

[3] Kastner-Klein P, Fedorovich E, Rotach MW. A wind tunnel study of organized and turbulent air motions in urban street canyons. J Wind Eng Ind Aerod 2001; 89(9): 849-61.

[4] Kalanda BD, Oke TR, Spittlehouse DL. Suburban energy balance estimates for Vancouver, B.C, using the Bowen ratio-energy balance approach. J Appl Meteor 1980; 19(7): 791-802.

[5] Grimmond CSB, Oke TR. Turbulent heat fluxes in urban areas: Observations and a local-scale urban meteorological parameterization scheme (LUMPS). J Appl Meteor 2002; 41(7): 792-810.

[6] Christen A, Vogt R. Energy and radiation balance of a central European city. Int J Climatol 2004; 24(11): 1395-421.

[7] Hage KD. Urban-rural humidity differences. J Appl Meteor 1975; 14(10): 1277-83.

[8] Richards K. Observation and simulation of dew in rural and urban environments. Prog Phys Geogr 2004; 28(1): 76-94.

[9] Dettwiller J, Changnon SA. Possible urban effects on maximum daily rainfall at Paris, St. Louis and Chicago. J Appl Meteor 1976; 15(5): 518-9.

[10] Shepherd JM, Pierce H, Negri AJ. On rainfall modification by major urban areas: Observations from space-borne radar on TRMM. J Appl Meteor 2002; 41(7): 689-701

[11] Grimmond CSB, King TS, Roth M, Oke TR. Aerodynamic roughness of urban areas derived from wind observations. BoundLay Meteor 1998; 89(1): 1-24.

[12] Roth M. Review of atmospheric turbulence over cities. Q J R Meteor Soc 2000; 126(564): 941-90.

[13] Morris CJG, Simmonds I, Plummer N. Quantification of the influences of wind and cloud on the nocturnal urban heat island of a large city. J Appl Meteor 2001; 40(2): 169-82.

[14] Hawkins TW, Brazel AJ, Stefanov WL, Bigler W, Saffell EM. The role of rural variability in urban heat island determination for Phoenix. Arizona. J Appl Meteor 2004; 43(3): 476-86.

[15] Basara JB, Hall PK, Schroeder AJ, Illston BG, Nemunaitis KL. Diurnal cycle of the Oklahoma city urban heat island. J Geophys Res 2008; 113: D20109.

[16] Bornstein RD. Observations of the urban heat island effect in New York City. J Appl Meteor 1968; 7(4): 575-82.

[17] Vukovich FM. A study of the effect of wind shear on a heat island circulation characteristic of an urban complex. Mon Weather Rev 1975; 103(1): 27-33.

[18] Oke TR. Boundary layer climates. London: Routledge 1987.

[19] Oke TR. The urban energy balance. Prog Phys Geogr 1988; 12: 471-508.

[20] Oke TR. City size and the urban heat island. Atmos Environ 1973; 7: 769-79.
[21] Oke TR. The energetic basis of the urban heat island. Q J R Meteor Soc 1982; 108: 1-24.

[22] Oke TR, Johnson GT, Steyn DG, Watson ID. Simulations of surface urban heat islands under ideal conditions at night Part 2: Diagnosis of causation. Bound-Lay Meteor 1991; 56: 339-58.

[23] Wilmers F. Effects of vegetation on urban climate and buildings. Energy Build 1990/91; 15-16: 507-14.

[24] Hart MA, Sailor DJ. Quantifying the influence of land-use and surface characteristics on spatial variability in the urban heat island. Theor Appl Climatol 2009; 95: doi: 10.1007/s00704-008-0017-5.

[25] Kukla G. Gavin J, Karl TR. Urban warming. J Clim Appl Meteor 1986; 25(9): 1265-70.

[26] Dabberdt W, Hales F, Zubrick S, et al. Forecast issues in the urban zone: Report of the $10^{\text {th }}$ Prospectus Development Team of the U.S. Weather Research Program. Bull Am Meteor Soc 2000; 81(9): 2047-64.

[27] Kalkstein LS, Jamason PF, Greene JS, Libby J, Robinson L. The Philadelphia hot weather-health watch/warning system: Development and application, Summer 1995. Bull Am Meteor Soc 1996; 77(7): 1519-28.

[28] Office of the federal coordinator for meteorological services and supporting research. Urban meteorology: meeting weather needs in the urban community. FCM-R22-2004. Washington, D.C., USA 2004.

[29] Mastrangelo G, Hajat S, Fadda E, Buja A, Fedeli U, Spolaore P. Contrasting patterns of hospital admissions and mortality during heat waves: Are deaths from circulatory disease a real excess or an artifact? Med Hyp 2006; 66: 1025-8.

[30] Ellefsen R. Mapping and measuring Buildings in the Canopy boundary layer in Ten U.S. Cities. Energy Build 1990/91; 15-16: 1025-49.

[31] Oke TR. Initial guidance to obtain representative meteorological observations at urban sites. 2004; WMO/TD No. 1250.

[32] Voogt JA, Oke TR. Complete urban surface temperature. J Appl Meteor 1997; 36(9): 1117-32.

[33] Auer AH. Correlation of land use and cover with meteorological anomalies. J Appl Meteor 1978; 17(5): 636-43.

[34] Stewart I, Oke TR. Classifying urban climate field sites by "Local Climate Zones": the Case of Nagano, Japan. Proceeding of $7^{\text {th }}$ Annual Int. Conf. on Urban Climate, Yokohama, Japan 2009.

[35] McPherson RA, Fiebrich C, Crawford KC, et al. Statewide monitoring of the mesoscale environment: A technical update on the Oklahoma mesonet. J Atmos Oceanic Tech 2007; 24(3): 30121.

[36] Basara JB,Illston BG,Fiebrich CA, et al. The Oklahoma city micronet. Meteorological applications. 2010; DOI:10.1002/met. 189.

[37] Brock FV, Crawford KC, Elliott RL, et al. The Oklahoma mesonet: A technical overview. J Atmos Oceanic Tech 1995; 12(2): 5-19.

[38] Shafer MA, Fiebrich CA, Arndt DS, Fredrickson SE, Hughes TW. Quality assurance procedures in the Oklahoma Mesonet. J Atmos Oceanic Tech 2000; 17(4) 474-94.

[39] Peterson TC, Owen TW. Urban heat island assessment: Metadata are important. J Climate 2005; 18(14): 2637-46.

[40] Oke TR. Towards better scientific communication in urban climate. Theor Appl Climatol 2006; 84: doi: 10.1007/s00704-005-0153-0.

[41] Sailor DJ. Simulated urban climate response to modifications in surface albedo and vegetative cover. J Appl Meteor 1995; 34(7): 1694-704.

[42] United States Census Bureau. "Metropolitan and micropolitan statistical area population and estimated components of change: April 1, 2000 to July 1, 2008," 2009. [Online]. Available from: http://www.census.gov/popest/metro/files/2008/CBSA-EST2008alldata.csv 